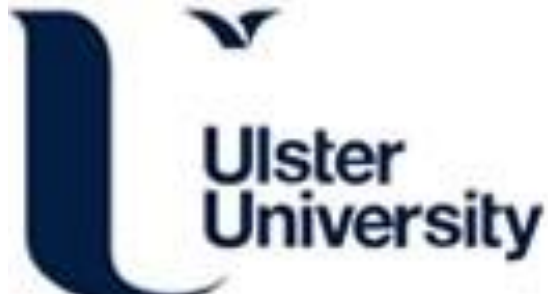

\section{Experimental study on capillary flow through polymer microchannel bends for microfluidic applications}

Mukhopadhyay, S., Roy, SS., Mathur, A., Tweedie, M., \& McLaughlin, JAD. (2010). Experimental study on capillary flow through polymer microchannel bends for microfluidic applications. Journal of Micromechanics and Microengineering, 20(5), 055018. https://doi.org/10.1088/0960-1317/20/5/055018

Link to publication record in Ulster University Research Portal

\section{Published in:}

Journal of Micromechanics and Microengineering

Publication Status:

Published (in print/issue): 01/01/2010

DOI:

10.1088/0960-1317/20/5/055018

\section{Document Version}

Publisher's PDF, also known as Version of record

\section{General rights}

Copyright for the publications made accessible via Ulster University's Research Portal is retained by the author(s) and / or other copyright owners and it is a condition of accessing these publications that users recognise and abide by the legal requirements associated with these rights.

\section{Take down policy}

The Research Portal is Ulster University's institutional repository that provides access to Ulster's research outputs. Every effort has been made to ensure that content in the Research Portal does not infringe any person's rights, or applicable UK laws. If you discover content in the Research Portal that you believe breaches copyright or violates any law, please contact pure-support@ulster.ac.uk. 
Experimental study on capillary flow through polymer microchannel bends for microfluidic applications

This article has been downloaded from IOPscience. Please scroll down to see the full text article.

2010 J. Micromech. Microeng. 20055018

(http://iopscience.iop.org/0960-1317/20/5/055018)

View the table of contents for this issue, or go to the journal homepage for more

Download details:

IP Address: 193.61.144.224

The article was downloaded on 16/04/2010 at 14:30

Please note that terms and conditions apply. 


\title{
Experimental study on capillary flow through polymer microchannel bends for microfluidic applications
}

\author{
S Mukhopadhyay, S S Roy, A Mathur, M Tweedie and J A McLaughlin \\ NIBEC, School of Engineering, University of Ulster, Jordanstown, Newtownabbey, \\ Co. Antrim BT37 OQB, UK \\ E-mail: s.sinha-roy@ulster.ac.uk and jad.mclaughlin@ulster.ac.uk
}

Received 27 November 2009, in final form 18 March 2010

Published 14 April 2010

Online at stacks.iop.org/JMM/20/055018

\begin{abstract}
Microchannel bends of rectangular cross-section were fabricated on polymethylmethacrylate (PMMA) by hot embossing, with a range of channel widths from $55 \mu \mathrm{m}$ to $400 \mu \mathrm{m}$. The capillary movement of the interface between air and dyed water through the microchannels was recorded and analysed. The microfluidic flow behaviour as a function of the channel aspect ratio was studied. The evaluated Reynolds number was always less than 1.0 in each channel of every device. The air-water interface velocity in the devices was proportional to the channel aspect ratio. The air-water interface velocity shows a prominent increase at $90^{\circ}$ separation angle. We observed an increasing trend of the air-water interface velocity with increasing channel aspect ratio. We have studied the separation of $10 \mu \mathrm{m}$ polystyrene microparticles using a simple microchannel bend structure. We have obtained approximately $100 \%$ efficiency for the combined separation and clog-free blocking of $10 \mu \mathrm{m}$ polystyrene microparticles using the above capillary flow behaviour in a modified microchannel bend structure.
\end{abstract}

(Some figures in this article are in colour only in the electronic version)

\section{Introduction}

In the recent past, microfabrication technologies have been extensively used to fabricate various microfluidic systems on glass, silicon, quartz and polymers. In order to develop any lab-on-a-chip system it is important to fabricate microchannels and chambers on polymers [1-5]. Hot embossing and maskless lithography are two useful techniques to fabricate microchannels and chambers on polymers, such as polydimethylsiloxane (PDMS) and polymethylmethacrylate (PMMA) [6-8]. PMMA has been used for the fabrication of microfluidic devices in bio-applications by surface modification [1, 2]. SU8 is also a useful photoresist for the fabrication of different MEMS devices and microstructures [3-5]. Leakage-free bonding between the microchannel and the channel lid is a challenge in the fabrication of microfluidic bioMEMS devices [9-11].

Passive capillary flow [12] has been used in microfluidic devices for biochemical analysis. Passive microfluidic devices have advantages over active devices from the point of view of integration, fabrication, cost and control [13]. Passive capillary flow is produced by surface tension effects so the flow speed can be controlled by modification of the wetting properties of the interior surface of the microchannel [14]. In general, capillary flow in microfluidic channels significantly depends on the channel aspect ratio. Many researchers have carried out fluid flow behaviour studies in microchannels with respect to the channel aspect ratio [15, 16]. In general, the maximum centreline velocity decreases with decreasing channel aspect ratio. Also, the Reynolds number is lower for the lower channel aspect ratio [16]. Recent studies show that microchannel bends are very useful for blood cell separation applications because of the centrifugal force produced on particles accelerated by the microchannel bend [17]. Also, several separation techniques for microparticles have been proposed by many researchers [18-25]. These methods may be applicable in lab-on-a-chip devices in other biological applications. For the practical application of any microfluidic devices it is essential to fabricate leakage/blockage-free 


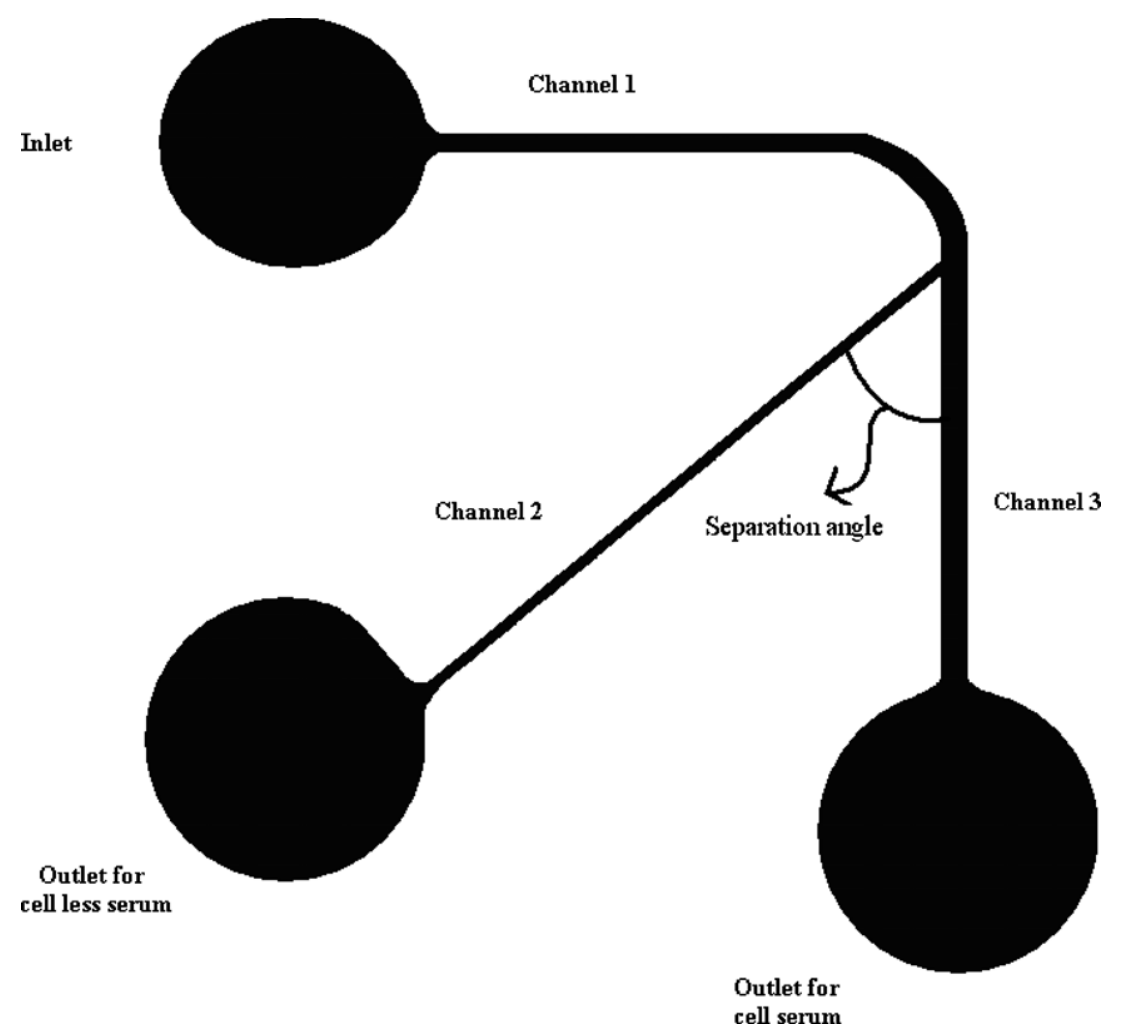

Figure 1. Schematic diagram of prototype microchannel bend for cell separation applications.

channels and have a clear understanding of fluid flow behaviour in microfluidic channels.

In this study, we have fabricated microchannel bends in PMMA with different microchannel widths. The effects of channel aspect ratios and different separation angles on the microfluidic flow were studied in the microchannel bend microfluidic devices. The filtration of $10 \mu \mathrm{m}$ polystyrene microparticles by capillary motion has been studied in both PMMA microchannel bend structures of the prototype design [17] and modified design (this work). A subsequent similar filtration study was then carried out on SU8 devices of the modified design.

\section{Experiment}

The prototype design of the microchannel bend is shown in figure 1. The schematic of figure 1 mainly represents the entrance channel (channel 1) coming from the inlet reservoir, a channel designed for passing filtered fluid (channel 2) and another channel designed for collecting unfiltered fluid (channel 3). All the channels considered here are threedimensional geometrical structures. The substrate materials for the microchannel under consideration are PMMA and SU8. The microchannel bend angle (angle between channel 1 and channel 3) was $90^{\circ}$ for all the devices. In this work, the microchannel bend structure has been tested to study the separation of $10 \mu \mathrm{m}$ polystyrene microparticles from a microparticle solution. In the following, we briefly discuss methods of fabrication of devices and fluidic measurements.

\subsection{Fabrication of microchannel bends}

An SU8 stamp on a silicon substrate was fabricated by maskless photolithography (for the production of a microchannel bend structure on PMMA) using standard SU8 processing methods [6-8, 26-30]. SU8 50 was, firstly, coated on a silicon substrate using a spin coater at 1000 RPM. After soft-bake, the SU8 was exposed for $25 \mathrm{~s}$ with a UV intensity of $311 \mu \mathrm{W} \mathrm{cm}{ }^{-2}$ using maskless photolithography for patterning. After post-exposure bake, the sample was developed by EC solvent and the sample was hard baked for good adhesion [6]. The above fabrication method is also applicable for the fabrication of SU8 microchannel bends.

PMMA channels were fabricated by hot embossing using the stamp [6, 22, 30-32]. For the fabrication process, an embossing temperature and pressure of $125^{\circ} \mathrm{C}$ and $10 \mathrm{kN}$, respectively, were used for an embossing time of $2 \mathrm{~min}$. The PMMA channel depth was measured as $32 \mu \mathrm{m}$ by a surface stylus profilometer. Finally, a direct bonding technique was used $[6,9]$ to produce PMMA devices. A bonding temperature and pressure of $90{ }^{\circ} \mathrm{C}$ and $10 \mathrm{kN}$, respectively, were used for a bonding time of $4 \mathrm{~min}$.

\subsection{Fluidic measurements}

We recorded and measured the characteristics of dyed water flow through the PMMA devices by a CMOS camera capturing 25 frames per second, and the corresponding resolution is 0.04 s. The microfluidic flow was recorded by flowing dyed water through the devices [6, 7], at a standard room temperature of $\sim 20-25^{\circ} \mathrm{C}$. The air-water interface velocities 
were measured directly from the recorded video clips of microfluidic flow [7]. The dyed water was prepared by mixing $5 \mathrm{~mL}$ of commercially available food dye into $50 \mathrm{~mL}$ of DI water. Static contact angles were measured by using dyed water in the sessile drop method, where the results were found to be equal to those of distilled water on the same material surfaces. A working liquid volume of $15 \mu \mathrm{L}$ was dispensed at the inlet to maintain the same entrance effect in each microfluidic flow experiment. The meniscus movements were measured along the centreline of the microfluidic channels. The shape of the meniscus in each microchannel was always vertical to the centreline of the microchannel.

For the microparticles separation experiment, a test solution was prepared by mixing $10 \mu \mathrm{L}$ of purchased solution $\left(1.8 \times 10^{7}\right.$ particles $\left.\mathrm{mL}^{-1}\right)$ with $3 \mathrm{~mL}$ of dyed water. The size of the microparticles was $10 \mu \mathrm{m}$. The test solution contains $6 \times 10^{4}$ particles $\mathrm{mL}^{-1}$ on average after sonication. The movements of the liquid front and moving microparticles behind the liquid front in different parts of the devices were captured by a video camera fitted to an optical microscope with a $10 \times$ objective lens.

\section{Results and discussion}

The effect of the microchannel aspect ratio on capillary flow was studied in the PMMA microchannel bends. In our previous studies, the liquid-air interface movement of the continuous dyed water flow through microchannels due to capillary action (surface tension at the interface between the liquid surface and the microchannel surface) was recorded and analysed [6-8]. The velocities of this air-water interface at different positions from the inlet (of different microfluidic devices) were calculated from the recorded video clips [6-8]. In this experimental investigation, we have calculated the liquid-air interface velocities in channels 2 and 3 just after the bend (figure 1). We have used the channel aspect ratio as the structural parameter and the Reynolds number as the flow parameter. The Reynolds number $(R e)$ for fluidic flow was defined and formulated as the ratio of inertial force to viscous force [16].

\subsection{Microfluidic flow in PMMA microchannel bends}

Microchannel bend microfluidic devices were fabricated by hot embossing [6], having the following two structures: (i) all the channel (channels 1, 2 and 3) widths were the same for any particular device, with a width from $55 \mu \mathrm{m}$ to $400 \mu \mathrm{m}$, (ii) all the channel (channels 1, 2 and 3) widths were different for any particular device and the widths of channel 1, channel 2 and channel 3 were $200 \mu \mathrm{m}, 100 \mu \mathrm{m}$ and $300 \mu \mathrm{m}$, respectively. The depth of all the channels in different PMMA devices was $32 \mu \mathrm{m}$ as measured by a surface stylus profilometer. The separation angle between channels 2 and 3 was defined to be $45^{\circ}$ as shown in figure 1 . In the PMMA devices, the channel width increased keeping the channel height fixed, so the channel aspect ratio decreased. The static water contact angle on the bottom surface of the PMMA channel was $79^{\circ}$ and that on the surface underneath the lid was $72^{\circ}$.

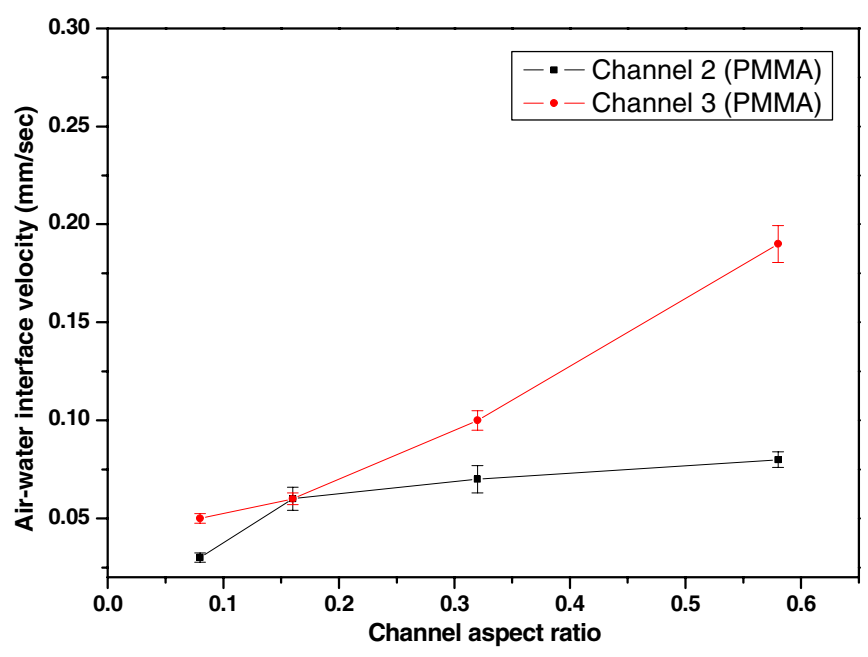

Figure 2. The dependence of local meniscus velocity on the channel aspect ratio for PMMA devices.

The dependence of the air-water interface velocity on the channel aspect ratio is shown in figure 2 for the PMMA devices of structure (i). In our experiments, the movement of the meniscus was slower through the channel of lower aspect ratio (figure 2), which was similar to that reported by Chen et al [15]. The higher friction constant in the channel of lower aspect ratio may be one reason for slower microfluidic flow [16]. If the fluid velocity is higher in channel 3 with respect to channel 2 , then a greater number of micro particles are expected to pass through channel 3 , so that the microparticle separation efficiency will be higher for the device [19]. The meniscus velocity was found to decrease in both channels 2 and 3 with increasing channel width for the PMMA devices of structure (i). We have also verified the dependence of microfluidic flow on the channel aspect ratio in the devices of structure (ii). Details of the flow characteristics are shown in table 1. The dependence of the microfluidic flow on the channel aspect ratio in the devices of structure (ii) was similar to that in the devices of structure (i). In figure 2, the difference between the interface velocities in channel 3 and channel 2 increased with increasing channel aspect ratio, and the interface velocity was higher in channel 3 due to higher centrifugal force on the liquid [17]. So, for the PMMA devices of structure (i), the centrifugal force on the liquid was higher in the bend region of higher channel aspect ratios.

We have also studied the effect of separation angle on the microfluidic flow through microchannel bends for structure (ii) as shown in figure 3. This effect was similar up to a separation angle of $70^{\circ}$. At a separation angle of $90^{\circ}$, the flow speed increased significantly in both of the channels 2 and 3 , the interface velocity in channel 3 was higher than that in channel 2, and also the difference between the interface velocities in channel 3 and 2 was much higher than that at other separation angles. So the centrifugal force may be higher on the dyed water through the $90^{\circ}$ bend region. Considering the meniscus velocity in channel 3 just after bend, we can conclude that the centrifugal force applied on the liquid in the bend region was higher for the higher channel aspect ratio (lower channel width). Chen et al [15] found a similar effect of the 
Table 1. Air-water interface velocity data of PMMA microchannel bends of mixed channel widths (separation angle $=45^{\circ}$ ).

\begin{tabular}{|c|c|c|c|c|c|c|c|}
\hline $\begin{array}{l}\text { Material of } \\
\text { bend } \\
\text { microfluidic } \\
\text { devices of } \\
\text { structure (ii) }\end{array}$ & $\begin{array}{l}\text { Widths of } \\
\text { channels } 1,2 \\
\text { and } 3(\mu \mathrm{m})\end{array}$ & $\begin{array}{l}\text { Aspect ratios } \\
\text { of channels } \\
1,2 \text { and } 3\end{array}$ & $\begin{array}{l}\text { Air-water } \\
\text { interface } \\
\text { velocity in } \\
\text { channel } 2 \\
\left(\mathrm{~mm} \mathrm{~s}^{-1}\right)\end{array}$ & $\begin{array}{l}\text { Reynolds } \\
\text { number in } \\
\text { channel } 2\end{array}$ & $\begin{array}{l}\text { Air-water } \\
\text { interface } \\
\text { velocity in } \\
\text { channel } 3 \\
\left(\mathrm{~mm} \mathrm{~s}^{-1}\right)\end{array}$ & $\begin{array}{l}\text { Reynolds } \\
\text { number in } \\
\text { channel } 3\end{array}$ & $\begin{array}{l}\text { Ratio between } \\
\text { air-water } \\
\text { interface } \\
\text { velocities in } \\
\text { channels } 2 \text { and } 3\end{array}$ \\
\hline PMMA & $\begin{array}{l}200,100 \text { and } \\
300\end{array}$ & $\begin{array}{l}0.16,0.32 \\
\text { and } 0.10\end{array}$ & $0.14( \pm 0.01)$ & 0.01 & $0.12( \pm 0.01)$ & 0.01 & 1.00: 0.86 \\
\hline
\end{tabular}

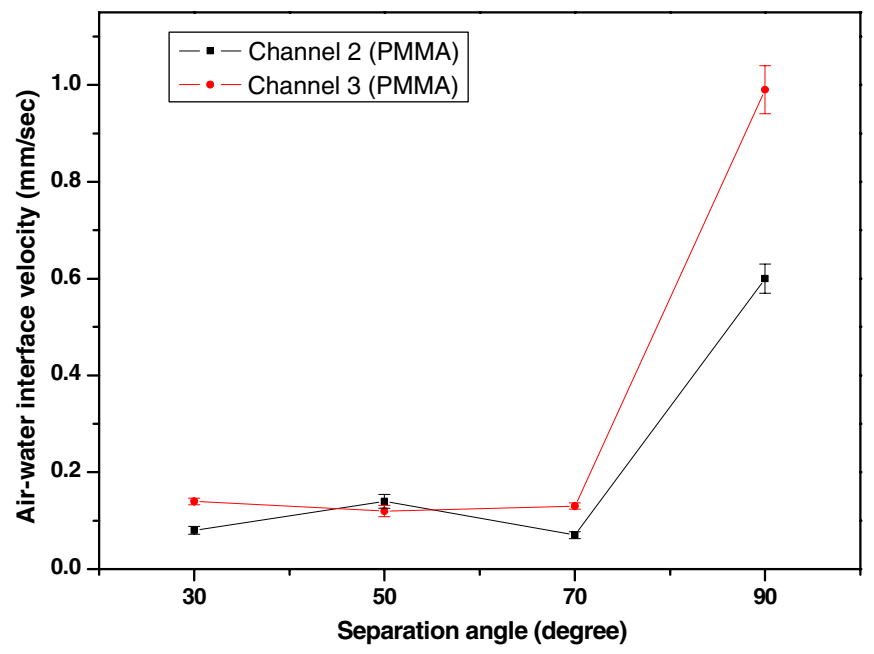

Figure 3. Variation of interface velocity with separation angle in PMMA microchannel bends.

centrifugal force on microfluidic flow by sharp microchannel turns. The level of bonding between the channel substrate and channel lid was tested after fabrication to avoid leakage during microfluidic flow [9]. Figure 4 shows a representative image of the microfluidic flow of dyed water in the PMMA device of $75 \mu \mathrm{m}$ channel width of structure (i). Figure 4 confirms no leakage in the devices. In figure 4 , the interface velocity was higher through channel 3 than in channel 2 for the device of structure (i), due to the effect of centrifugal force on the liquid in the bend region. As shown in table 1 , the interface velocity through channel 2 was higher than that in channel 3 for the device of structure (ii). So, in a single device of different aspect ratio channels, the effect of the aspect ratio was dominant over the effect of centrifugal force.

\subsection{Separation of microparticles by structurally (design) modified microchannel bends}

In the prototype microchannel bend structure (figure 1) for blood particle separation applications, the width of channel 2 was kept much lower than that of channel 3, so that the higher volume fraction passes through channel 3 [19]. In this study, the widths of channels 1, 2 and 3 were set at $200 \mu \mathrm{m}$, $100 \mu \mathrm{m}$ and $400 \mu \mathrm{m}$, respectively, for determining the effect of the channel aspect ratio on microfluidic flow. We have carried out an experimental study on the separation of $10 \mu \mathrm{m}$ polystyrene microparticles through the PMMA microchannel bend (figure 1) to achieve maximum separation efficiency. We have obtained up to $86 \%$ (approximately) separation efficiency

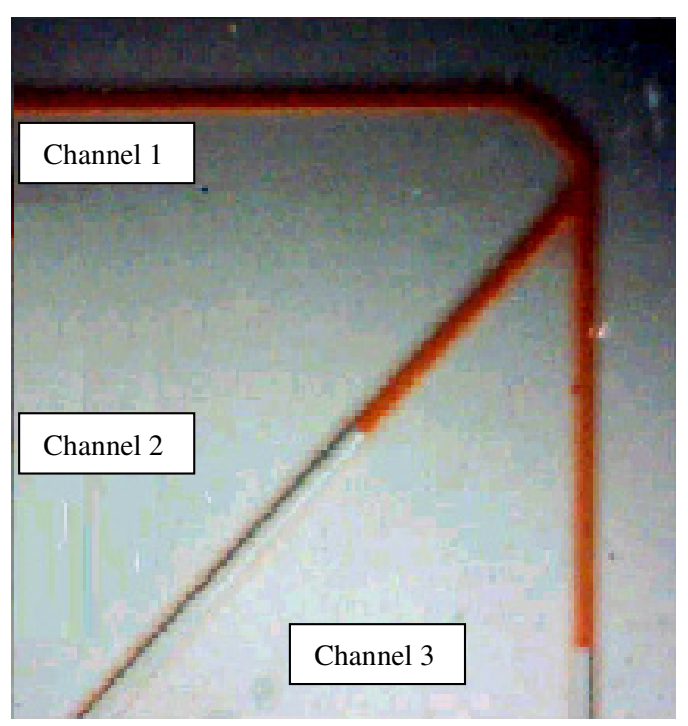

Figure 4. Microfluidic flow through the PMMA microchannel bend of the $75 \mu \mathrm{m}$ channel width of each of the channels 1,2 and 3 .

by this structure. Other research groups also obtained up to $90 \%$ separation efficiency by using highly diluted blood [17] by pressure-driven flow. In order to decrease further the percentage of blood cells passing into the channel and on to the sensor, we modified the prototype microchannel bend structure according to the schematic of figure 5. In brief, the device of figure 5 was designed by the addition of the following structural modifications to the simple microchannel bend (figure 1): (i) sudden expansion of channel width at the entrance of chamber 1 in channel 2, (ii) addition of micropillars in chamber 1, and (iii) side channel (channel 4) at the end of chamber 1 . We maintained the same separation angle of $45^{\circ}$ in both of the designs of figures 1 and 5 . The prototype design in figure 1 involved only the effect of centrifugal force on the microfluidic flow, at the bend region before the junction, to separate microparticles from the plasma, but our design has the addition of other components in channel 2 to achieve maximum combined separation and blocking efficiency. These significant effects are based on the channel aspect ratio and micropillars.

In the modified devices we achieved $100 \%$ combined separation and blocking efficiency of $10 \mu \mathrm{m}$ polystyrene microparticles. In figure 6, the optical images for PMMA device (figure 5) have been shown for microparticle separation. If no microparticle is found in the observation chamber when the meniscus reaches the outlet of channel 2 , then the separation efficiency is considered to be $100 \%$. The lower 


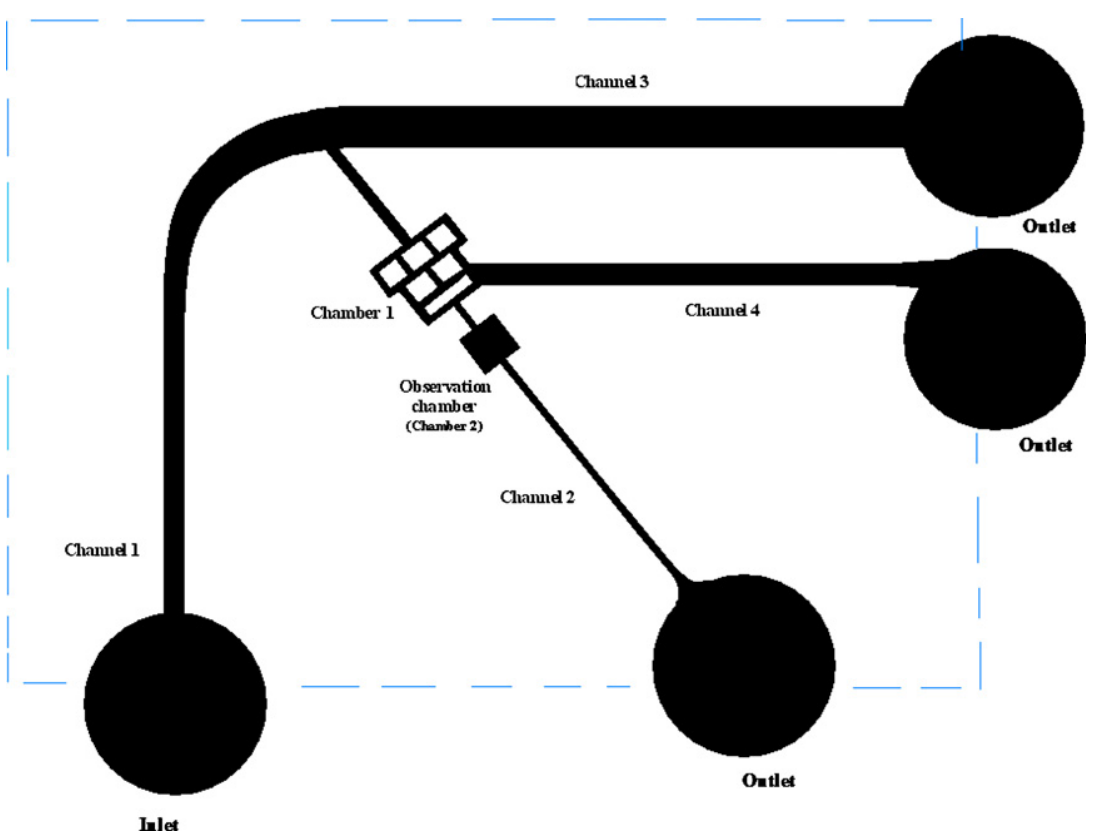

Figure 5. Schematic diagram of the modified (design) microchannel bend.

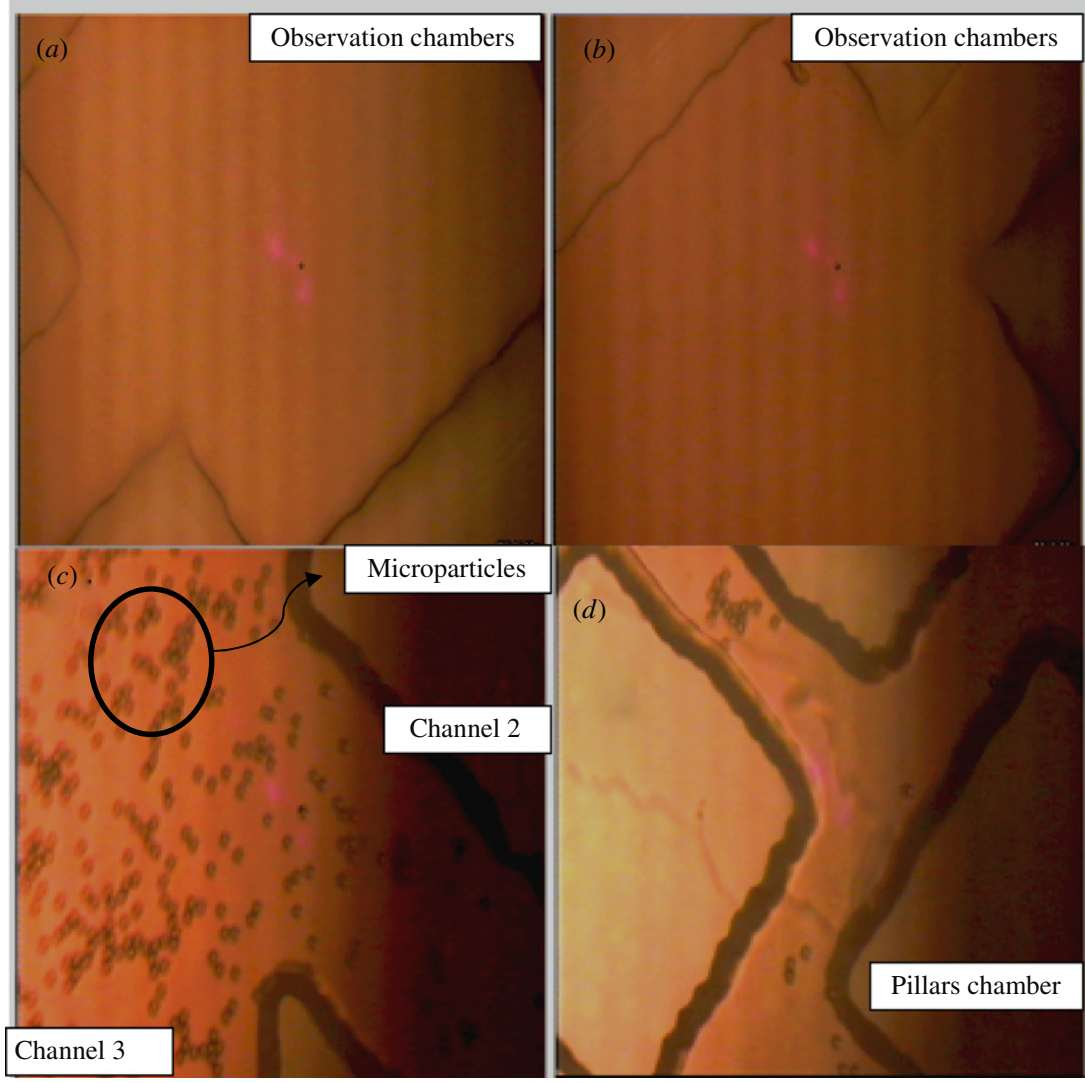

Figure 6. Optical microscopic images of microparticles' separation through modified (design) microchannel bend PMMA devices. Images were taken $(a)$ at lower half of the observation chamber, $(b)$ at upper half of the observation chamber, $(c)$ at the junction of channels 3 and 2 , $(d)$ at the pillar chamber.

half of the observation chamber is shown in figure $6(a)$, after achieving $100 \%$ efficiency in one specific test of the PMMA device shown in figure 5, and the upper half of the same observation chamber, after the same test, is shown in figure $6(b)$. The video image (captured by the CCD camera viewing through the optical microscope) of the $10 \mu \mathrm{m}$ particle flow just after the bend, at the junction of channels 2 and 3 in the PMMA device, is shown in figure 6(c). The blockage of $10 \mu \mathrm{m}$ microparticles between the micropillars in chamber 1 is shown in figure $6(d)$. The square-shaped observation chamber 
in figure 5 has a side length of $400 \mu \mathrm{m}$. After achieving a combined $100 \%$ separation and blocking efficiency of $100 \%$ in the PMMA devices, we also tested SU8 devices of similar design (figure 5) and obtained the same overall efficiency. The SU8 devices were fabricated by maskless lithography and indirect bonding techniques [7]. The channel widths, pillar side length and inter-pillar distances were similar to those of the PMMA devices. In SU8 devices, both the channel heights and pillar heights were $60 \mu \mathrm{m}$.

In this section, we have explained the reason for obtaining a combined separation and blocking efficiency of $100 \%$ in modified devices and the possible applications of this. We used one sudden expansion of the channel width at the entrance of chamber 1 in channel 2. The meniscus movement was slower after the sudden expansion due to the following reasons: (i) the channel aspect ratio reduces just after the sudden expansion which reduces the flow speed, (ii) the area of material surface to be wetted is increased by the presence of micropillars and increased channel widths. These make significantly enhanced flow variation between channels 2 and 3, so a large amount of particles pass through channel 3 with a major amount of liquid. The micropillars also used to block the residual microparticles in channel 2. In the devices of both materials, the height of the micropillars is equal to the height of the microchannel so that there is no gap between the micropillars (chamber 1) and channel lid. As a result, there is no possibility of passage of microparticles above the micropillars. The blocked microparticles passed through channel 4 (see figure 5). Considering 100\% separation/blocking efficiency in both SU8 and PMMA devices of different channel heights, we may conclude that the secondary separation chamber was the effective step for the improvement of separation efficiency. Our device has the following advantages: (i) surface-driven (i.e. passive) microfluidic flow was used for the total device operation; (ii) only a small amount of liquid $(\sim 15 \mu \mathrm{L})$ is required for microparticle separation. The design parameters are set in such a way that the device can be used as a blood filter in future. RBCs (red blood cells) have an average diameter range from 7 to $9 \mu \mathrm{m}$, and WBCs (white blood cells) have an average diameter range from 6 to $20 \mu \mathrm{m}[18$, 21, 25]. For future application of this modified design in blood filtration, the channel widths and interpillar distances should be significantly higher than RBC or WBC size to avoid channel clogging $[22,23]$. The channel width $(\geqslant 100 \mu \mathrm{m})$, inter-pillar and pillar-channel wall distances $(\sim 60 \mu \mathrm{m})$ for our microchannel bend could be useful in a lab-on-a-chip system.

\section{Conclusion}

Leakage-free PMMA microchannel bends were fabricated using a hot embossing technique. The channel aspect ratio and centrifugal force were two important factors in controlling laminar flow and microparticle separation in the microchannel bends. The flow velocity increased with increasing channel aspect ratio for the PMMA devices. At a separation angle of $90^{\circ}$ in PMMA microchannel bends, the meniscus velocity strikingly increased compared to the situation at lower separation angles. We modified the prototype microchannel bend structure and achieved 100\% efficiency for the separation/blocking of $10 \mu \mathrm{m}$ polystyrene microparticles for similar PMMA and SU8 devices. The modified structure can be applied in a point-of-care device, where RBCs and WBCs needed to be filtered from whole blood to avoid fouling the sensor.

\section{References}

[1] Kim J, Kim P, Lee S H, Suh G Y and Yoon J 2006 Proc. IEEE Conf. on Bio Micro and Nanosystems p 97

[2] Zhu X, Liu G, Xiong Y, Guo Y and Tian Y 2006 J. Phys.: Conf. Ser. 34875

[3] Conradie E H and Moore D F 2002 J. Micromech. Microeng. 12368

[4] Nordström M, Marie R, Calleja M and Boisen A $2004 \mathrm{~J}$. Micromech. Microeng. 141614

[5] Yang S and Lin Y 2007 J. Micromech. Microeng. 172447

[6] Mathur A, Roy S S, Tweedie M, Mukhopadhyay S, Mitra S K and McLaughlin J A 2009 Curr. Appl. Phys. 91199

[7] Mukhopadhyay S, O'Keeffe P, Mathur A, Tweedie M, Roy S S and McLaughlin J A 2009 J. Surf. Sci. Nanotech. 7330

[8] Saha A A, Mitra S K, Tweedie M, Roy S and McLaughlin J A 2008 Microfluid. Nanofluid. 7451

[9] Tsao C and DeVoe D 2009 Microfluid. Nanofluid. 61

[10] Yu L, Tay F E H, Xu G, Chen B, Avram M and Iliescu C 2006 J. Phys.: Conf. Ser. 34776

[11] Bilenberg B, Nielsen T, Clausen B and Kristensen A $2004 \mathrm{~J}$. Micromech. Microeng. 14814

[12] Ichikawa N, Hosokawa K and Maeda R 2004 J. Colloid Interface Sci. 280155

[13] Chew M, Teo W, Xie L, Premachandran C S, Wong W H, $\mathrm{Xu}$ D and Yao Q 2006 Proc. 8th IEEE Electronics Packaging Technology Conf. 2006 p 448

[14] Suk J and Cho J 2007 J. Micromech. Microeng. 17 N11

[15] Chen Y, Tseng F, ChangChien S, Chen M, Yu R and Chieng C 2008 Microfluid. Nanofluid. 5193

[16] Papautsky I, Gale B K, Mohanty S, Ameel T A and Frazier A B 1999 Proc. SPIE 3877147

[17] Blattert C, Jurischka R, Tahhan I, Schoth A, Kerth P and Menz W 2004 Proc. 26th Ann. Int. Conf. of the IEEE EMBS (San Francisco, CA, USA) p 2627

[18] Zheng S, Liu J and Tai Y 2008 J. Micromechanical Syst. 171029

[19] Roberts B and Olbricht W 2003 AIChE J. 492842

[20] Yamada M and Seki M 2005 Lab Chip 51233

[21] Zheng S, Yung R, Tai Y and Kasdan H 2005 Proc. 18th IEEE Int. Conf. MEMS (Miami Beach, FL) p 851

[22] Li J, Liu C, Dai X, Chen H, Liang Y, Sun H, Tian H and Ding X 2008 J. Micromech. Microeng. 18095021

[23] Carlo D, Irimia D, Tompkins R and Toner M 2007 PNAS 10418892

[24] Sun C, Migliorini C and Munn L 2003 Biophys. J. 85208

[25] Zhu J, Cheng J and Ang S 2006 J. Phys.: Conf. Ser. 34734

[26] Ruano-López J, Aguirregabiria M, Tijero M, Arroyo M, Elizalde J, Berganzo J, Aranburu I, Blanco F and Mayora K 2006 Sensors Actuators B 114542

[27] Sato H, Matsumura H, Keino S and Shoji S $2006 J$. Micromech. Microeng. 162318

[28] Campo A and Greiner C 2007 J. Micromech. Microeng. 17 R81

[29] Sameoto D, Tsang S, Foulds I, Lee S and Parameswaran M 2007 J. Micromech. Microeng. 171093

[30] Becker H and Locascio L 2002 Talanta 56267

[31] Becker H and Heim U 2000 Sensors Actuators 83130

[32] Datta P and Goettert J 2007 Microsyst. Technol. 13265 